\title{
\begin{tabular}{l|l} 
Mibraries & DSpace@MIT
\end{tabular}
}

\author{
MIT Open Access Articles
}

\section{Building Fast to Think Faster: Exploiting Rapid Prototyping to Accelerate Ideation During Early Stage Design}

The MIT Faculty has made this article openly available. Please share how this access benefits you. Your story matters.

Citation: Neeley, W. Lawrence, Kirsten Lim, April Zhu, and Maria C. Yang. “Building Fast to Think Faster: Exploiting Rapid Prototyping to Accelerate Ideation During Early Stage Design." Volume 5: 25th International Conference on Design Theory and Methodology; ASME 2013 Power Transmission and Gearing Conference (August 4, 2013).

As Published: http://dx.doi.org/10.1115/DETC2013-12635

Publisher: ASME International

Persistent URL: http://hdl.handle.net/1721.1/120026

Version: Final published version: final published article, as it appeared in a journal, conference proceedings, or other formally published context

Terms of Use: Article is made available in accordance with the publisher's policy and may be subject to US copyright law. Please refer to the publisher's site for terms of use. 
August 4-7, 2013, Portland, Oregon, USA

\section{DETC2013-12635}

\section{BUILDING FAST TO THINK FASTER: EXPLOITING RAPID PROTOTYPING TO ACCELERATE IDEATION DURING EARLY STAGE DESIGN}

\author{
W. Lawrence Neeley, Jr. \\ Engineering Design \& Entrepreneurship \\ Olin College of Engineering \\ Needham, MA, USA
}

\author{
April Zhu \\ Environmental Studies \\ Wellesley College \\ Wellesley, MA, USA
}

\author{
Kirsten Lim \\ Department of Mechanical Engineering \\ Massachusetts Institute of Technology \\ Cambridge, MA, USA
}

\author{
Maria C. Yang \\ Department of Mechanical Engineering and \\ Engineering Systems Division \\ Massachusetts Institute of Technology \\ Cambridge, MA, USA
}

\begin{abstract}
While rapid prototyping has proved to be an invaluable resource for expediting particular phases of the design process, its decreasing cost of operation and increasing accessibility reveal greater potential for these tools to substantially impact the design process itself. While many studies have investigated the advantages of creating and interacting with physical models in engineering design, this study explores the value of delaying decisions and pursuing many prototypes as it applies to individual designers in the earliest phases of the design process. Inspired by The Second Toyota Paradox, we propose the use of Kolb's theory of experiential learning to reconcile the implications of set-based rather than point-to-point engineering with the value of an individual designer's learning through interactions with concrete objects. We compared the performance of engineering students in a design challenge. The independent variable was the number of prototypes the participant was required to produce in the first iteration. Participants who were instructed to produce more prototypes in the same amount of time in which their control counterparts were only required to produce one expressed much higher levels of time constraint and dissatisfaction in their primary prototypes. However, multiple-design participants' prototypes performed better, showed significantly greater improvement between iterations; in addition, satisfaction increased significantly after completion of the final prototype. We look to Kolb's theory of experiential learning and an individualized application of corporate concurrent engineering to suggest a
\end{abstract}

new design process heavy in low-fidelity, low-quality physical models in early design stages.

\section{INTRODUCTION}

The paradigms of design that dictate our product development processes today reflect contemporary affordances of technology. Simon [1] defined the process as the generation of all alternative solutions and the subsequent testing of these alternatives against an array of constraints. Bucciarelli [2] recognized design as a "social process," a bottom-up approach that shifted focus from engineering a perfect solution to "formulating the right problem" [3]. Furthermore, Owen [4] asserted that "design is the creation process through which we employ tools and language to invent artifacts and institutions. As society has evolved, so has our ability to design."

Design is a socio-technical process. Within this process, exploration of alternatives within the problem space is at least as important as convergence within a solution space. In all design efforts, the tools we employ critically influence the nature, efficacy and outcome of the work undertaken. It is this fundamental relationship between the processes and products of design and the tools used in their pursuit, that we seek to experimentally explore.

In recent years, rapid prototyping has assumed an increasingly important role in design. The value of prototyping for specific stages of a design has long been recognized as an efficient way to [5-8] explore a design's performance and communicate an idea to other users, managers, and other stakeholders [9-13]. Rapid prototyping can be faster, more 
precise, and less laborious than traditional methods of creating models. However, by expediting the process of fabrication, rapid prototyping has allowed for the fast evaluation of realistic, preliminary prototypes as well, thereby creating new opportunities for designers to physically interact with prototypes even in early stages of design, when quantity of ideas rather than only quality may be key.

We are attempting to realign existing design processes, specifically early stages such as ideation, more fully with the affordances of modern tools. So-called rapid prototyping tools have impacted the design process by fulfilling their original purpose of accelerating prototype fabrication. However, less attention has been given to how these tools may substantially affect the strategies used by designers during the earlier stages of the design process. Beyond exploring how rapid prototyping alters the physical mechanisms of design production, we seek to investigate how it may affect the mental mechanisms of design conception.

Here, we investigate the potential advantages of early stage design divergence using physical models produced timeefficiently via rapid prototyping. As designers withhold judgment during the brainstorming stage in order to interact with as many ideas as possible, designers in the age of rapid prototyping may also optimize learning by interacting with many physical representations of their early ideas, and perhaps even avoid fixation [14]. Instead of relying on rapid prototyping merely to fabricate and present developed ideas, designers can explore their early ideas in three dimensions. As a result, there is potential for the emergence of a novel design process paradigm: rather than conferring iterative focus to one thread of designs, focus is spread among several divergent design sets and convergence is delayed.

This paper describes a controlled experiment comparing two sets of design participants in a design-and-assemble exercise with the goal of answering the following questions:

- Does the creation of more initial prototypes correlate to better final design outcome?

- Does the creation of more initial prototypes relate to better design outcome in subsequent iterations?

- How does generating more initial prototypes affect a designer's perceptions of the design process and the artifact?

\section{BACKGROUND}

The concept of early prototype-based design process is not new. This approach has been executed in a corporate context in Toyota's development process, which Ward et al. coined "The Second Toyota Paradox" [15]. This paradigm emphasizes the simultaneous development of multiple alternative sets of design, or set-based concurrent engineering, rather than a single design that progresses iteratively from one point to the next. In Toyota's case, concurrent engineering proved to be a successful method of producing innovative products in an efficient manner [16].
We conjecture that, similar to the way in which Toyota delayed design decisions and pursued more prototypes, individual designers may also be able to harness increasingly accessible rapid prototyping tools to diverge in the prototyping stage [17]. If this is possible, design development may be optimized by shifting emphasis to experiential-heavy stages of design, where many sets of early prototypes-"half-baked ideas"-are concurrently developed before making a design decision and proceeding with one prototype. However, whether or not the principles behind the Second Toyota Paradox, which operate between groups of people, are applicable to individual designers as well, has not received much investigation.

The development of prototypes has clear engineering relevance to the artifact being developed, but this filters through the lens of the designer. The designer assesses the performance of a prototype and then proposes design changes accordingly in a phase of re-design. It is in this context that we introduce Kolb's experiential learning theory to offer insight on the cognitive mechanisms involved in divergent prototyping. Kolb defined learning as "the process whereby knowledge is created through the transformation of experience" [18]. Learning is achieved when personal concrete experiences are integrated into existing abstract concepts that subsequently feed back into newer experiences, repeating the process. Kolb's theory has been extensively studied to explain processes of learning [19, 20] and applied to learning models in design [4]. We propose the use of Kolb's theory of experiential learning to reconcile the paradigm-shifting implications of set-based rather than point-to-point engineering with the value of learning through interactions with concrete objects.

Kolb argues that knowledge, rather than a collection of facts and habits, is a continuously modified balance of adaptive abilities shaped and reshaped by experience. In his words, "Ideas are not fixed and immutable elements of thought but are formed and re-formed through experience [18]." Learning is achieved at the intersection of four modes of adaptive ability which describe the ways in which one can interact with his environment. Although similar elements appear in the work of Dewey, Lewin, and Piaget, the abilities in Kolb's model are "concrete experience abilities (CE), reflective observation abilities (RO), abstract conceptualization abilities (AC), and active experimentation (AE)". As the learner moves from one of these dialectically opposed modes to the other, she is required to reconcile these. When neither pole dominates and these opposing learning forces are harmonized, there is space for "creative synthesis."

The design process has itself been likened to learning models [4]. It is fundamentally an iterative process of resolving physical elements with functional ones [21], and like Kolb's experiential learner, designers must also balance passive observation with active experimentation. To elaborate: when a designer is compelled to conceive and fabricate multiple "halfbaked" prototypes, she is forced to reconcile the abstract functional goals of her design challenge with the physical limitations of the concrete reality before her. As she explores these physical models, she is forming and re-forming ideas as a 
function of her experience. She cycles through all adaptive ability stages (CE, RO, AC, AE) and only begins to converge her design space when all of these possibilities have been introduced and explored in this experiential method. Contrast this to a conventional, point-to-point iteration method in which the designer may begin to shrink the design space and make decisions before exploring the idea in its concrete form [22]. Furthermore, even if the idea(s) were fabricated and explored as physical models, the conventional iterative approach does not allow the designer the full benefit of experientially learning with all possibilities from the beginning.

It is this theoretical framing that motivates our experimentation.

\section{METHOD}

\subsection{PARTICIPANTS}

The 39 participants (19 female, 20 male) in this experiment were 27 undergraduates and 12 graduate engineering students at a U.S. university. The majority of these participants had some exposure to design ("Taken design class/program, hobbies, etc."), as indicated by the survey responses collected at the end of the experiment.

\subsection{DESIGN PROBLEM}

The design task was to build a cardboard structure that was as tall as possible using only one A4-sized sheet of corrugated cardboard. The only physical constraint was that the tower must be free-standing, that is, it could not lean against another object or latch onto the table.

Participants were provided with the following materials to complete this task: Design prompt description, white 8.5 " $\mathrm{x} 11$ " copy paper, an eraser, wooden pencils, Sharpie markers (Thin and Regular tip), Whitelines ${ }^{\circledR}$ A4 grid paper, 6" steel ruler, 20" steel ruler, hobby knife, and countdown timer.

\subsection{EXPERIMENTAL DESIGN}

Individual participants were asked to design a structure in two iterations, each comprised of an idea generation stage followed by a prototype fabrication/assembly stage. The independent variable was the number of prototypes submitted during the idea generation stage of the first iteration. During that 30-minute period, the control group was instructed to generate one design (1-Design), while the 5-Design group was instructed to generate up to five. The overall experiment duration was the same for all participants.

The following dependent variables were recorded: performance of the preliminary prototype, performance of the final prototype, basic tower structure, experienced difficulty of the design problem. Prototype performance was determined by its free-standing height, measured perpendicular to the base surface. A mid-point survey issued after submission of the preliminary prototype(s) and a final survey issued after submission of the final prototype documented participants' reflections and perceptions about the preceding task. Participants' progress was visually documented with a camera set up to take a photo of the desktop every 30 seconds.
Table 1. Experimental Design

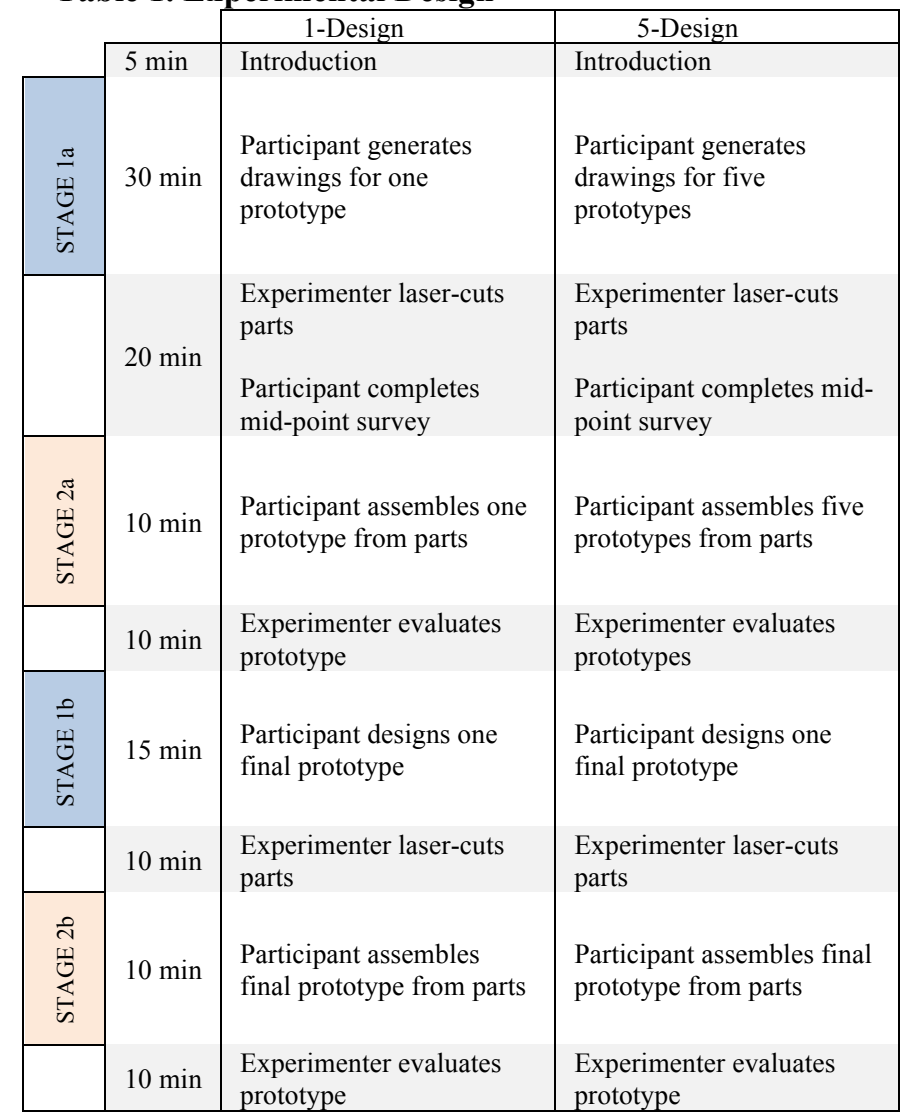

Stage 1: Participants were given thirty minutes to sketch their ideas (no physical prototyping) and to draw a template of pieces for their designs on A4 sheets of paper. At the beginning of this first stage, participants were given instructions based on the group, 1-design or 5-design, that they were randomly assigned.

- Participants in the 1-design case were told to design and create a template for one idea by the end of the thirty minutes.

- Participants in the 5-design case were told to design and create template(s) for five ideas by the end of the thirty minutes.

Stage 2: Each template was then scanned by the experimenter (not the participant) using a flatbed scanner and imported into Adobe Illustrator. The drawing was traced in Adobe Illustrator to create a vector file of the scan. This vector file was then used to laser cut the template design directly onto an A4 sheet of cardboard. While the digitization took place, the participants were asked to complete a short midpoint survey about their thoughts on their design so far. More specifically, this survey asked participants to evaluate how difficult they perceived the tasks to be and how satisfied they felt with their work up to that point on a 7-point Likert scale.

After receiving the laser cut pieces, participants were given twenty minutes to build their towers. During this period, 
participants were provided with a hobby knife to clean up any of the laser cutter edges and modify parts as desired. When completed, the prototype towers were measured and photographed. If more than one prototype tower was constructed in the 5-design case, the tallest tower was photographed and measured.

Participants then completed a second iteration of the process, under a tighter time constraint of fifteen minutes. In this iteration, all participants were only to create one prototype.

This final prototype was fabricated using the same methods as the first. However, participants were only allowed 10 minutes to assemble their final prototype.

After assembly was completed, participants were given a final survey and briefly interviewed about their thought process during the experiment. Again, the final survey asked participants to rank the difficulty of the tasks and how satisfied they felt with their work on a 7-point Likert scale. The final height of the tower was recorded, and the tower was photographed. For towers that were not successfully completed in the time allotted (unstable towers), a height was not assigned, since a value of 0 would indicate that the participant did not build any portion of a tower.

This experiment was formatted to standardize the time spent in each stage of the design process. However, if a participant finished an activity before the time allotted was used, they were allowed to proceed to the next section. Table 1 shows the general flow of the experiment, as well as time durations for each activity.

Surveys were administered at the end of each iteration to gauge, on a 7-point Likert scale, perceptions of time constraint, difficulty of task, satisfaction with design, and overall reactions. The surveys also collected information about the participant's demographics, previous design experience, and self-reported proficiency in various prototyping methods.

\section{RESULTS}

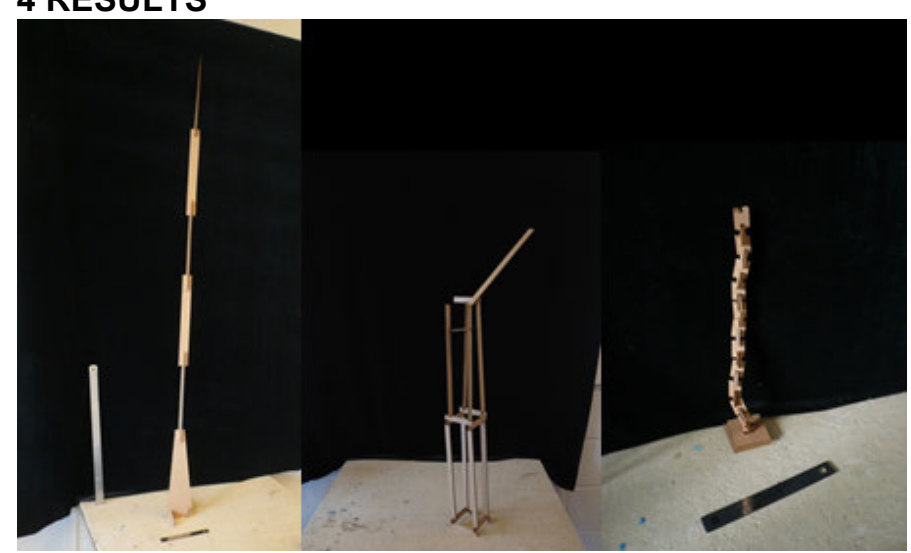

Figure 1. Examples of successful, free-standing tower structures.

\subsection{COMPARISON OF INITIAL DESIGN AND RE- DESIGN}

After completing Stage 1a, 5-Design participants perceived significantly greater time constraint (Student's unpaired two-tailed t-test, $p=0.0173$ ) and somewhat lower levels of satisfaction (Student's unpaired two-tailed t-test, $p=0.0632$ ) than their 1 -Design counterparts, as expressed in responses to the midpoint survey.

However, 5-Design participants were also significantly more satisfied with their final prototype than with their first prototype (Student's paired two-tailed t-test, $p=0.0632$; Table 4). No difference in satisfaction was observed between prototypes for 1-Design participants (Student's paired twotailed t-test $p=0.274$ ).

5-Design participants showed significant improvement in their design between iterations, as the change in height between first and final prototypes for 5-Design participants was significantly greater than that of 1-Design participants (Student's paired two-tailed t-test, $p=0.0113$; Table 2). The $\mathrm{p}$ value calculated for the 1 -design case was 0.2789 , indicating that there is not statistically significant correlation between iterations in the 1-Design case.

Table 2. Mean heights after initial and final prototypes

\begin{tabular}{|c|c|c|c|}
\hline & $\begin{array}{l}\text { Initial Height (in) } \\
(\text { Mean } \pm \text { SE) }\end{array}$ & $\begin{array}{l}\text { Final Height (in) } \\
(\text { Mean } \pm \text { SE) }\end{array}$ & \\
\hline 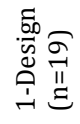 & $27.33 \pm 4.01$ & $30.26 \pm 3.22$ & $p=0.2789$ \\
\hline 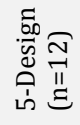 & $31.55 \pm 6.28$ & $40.53 \pm 6.21$ & $p=0.0113$ \\
\hline
\end{tabular}

The distribution of heights between iterations for both the 1-Design case and 5-Design case are shown in Figure 2 and Figure 3, respectively.

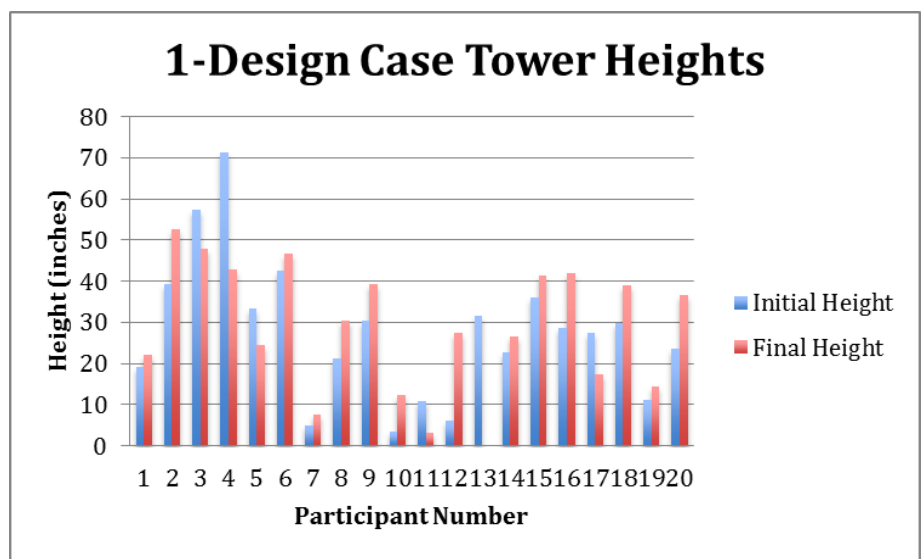

Figure 2. 1-Design Tower Heights. Participants missing an initial or final height did not build a successful tower or did not have enough time to complete construction. 


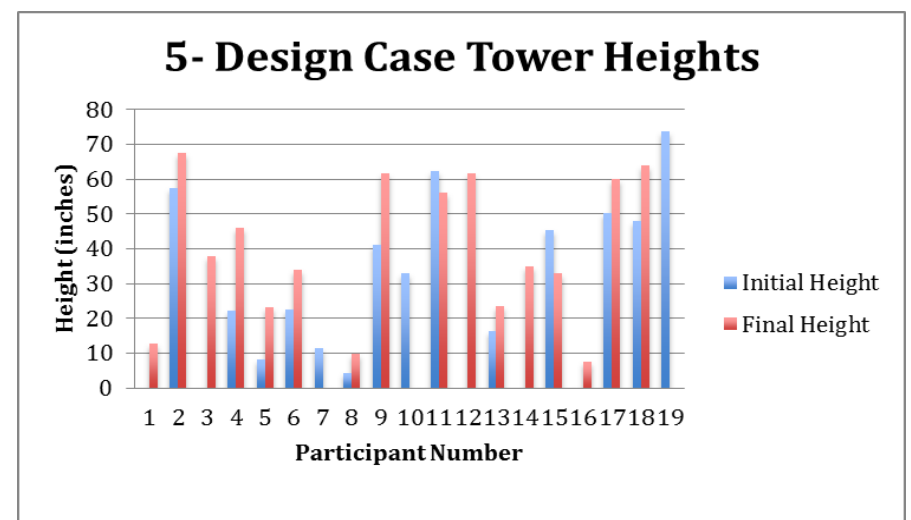

Figure 3. 5-Design Tower Heights. Participants missing an initial or final height did not build a successful tower or did not have enough time to complete construction.

\subsection{FINAL HEIGHT COMPARISON}

The differences in average final heights for the 1-design (30.26 inches) and 5-design (40.53 inches) cases are shown in Table 2. The average 5-design height is greater than the 1design case. However, a Mann-Whitney U test was conducted to evaluate the statistical significance of this difference. The $\mathrm{U}$ calculated for this data set was 189 , with a $\mathrm{z}$ value of $-1.21, \mathrm{P} 1$ value of 0.1131 , and a $\mathrm{P} 2$ value of 0.2263 . The range for $\mathrm{U}$ values for an alpha of 0.05 were 101-203, so the data set gathered does not appear to be statistically significant. For the final heights, the difference between 5-design was not significantly higher than the 1-design case.

\subsection{SURVEY ANALYSIS}

Tables 3 and 4 summarize the results of the surveys. Items in bold indicate statistically significant differences between the 1-Design and 5-Design groups or between first and second iterations of a design.

Table 3. Comparison of 1-Design and 5-Design Survey Results. Surveys measured on a 7-point Likert scale. 5-Design participants expressed significantly higher levels of time constraint (Student's t-test, $p<0.0001$ ) and lower levels of satisfaction $(p=0.0606)$.

\begin{tabular}{|c|c|c|c|}
\hline & Survey Question & $\begin{array}{l}\text { 1-Design } \\
(\text { Mean } \pm \text { SE) }\end{array}$ & $\begin{array}{l}\text { 5-Design } \\
(\text { Mean } \pm \text { SE })\end{array}$ \\
\hline \multirow{3}{*}{ 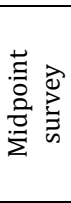 } & $\begin{array}{l}\text { How would you rate the technical } \\
\text { difficulty of the design task? }\end{array}$ & $3.7 \pm 0.25$ & $3.7 \pm 0.30$ \\
\hline & $\begin{array}{l}\text { How difficult was it to complete the } \\
\text { task in the allotted time? }\end{array}$ & 0.34 & 0.31 \\
\hline & $\begin{array}{l}\text { How satisfied are you with your } \\
\text { design? }\end{array}$ & .20 & 0.31 \\
\hline \multirow{3}{*}{ 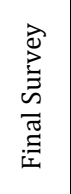 } & $\begin{array}{l}\text { How would you rate the technical } \\
\text { difficulty of the design task? }\end{array}$ & 0.23 & $3.9 \pm 0.23$ \\
\hline & $\begin{array}{l}\text { How difficult was it to complete the } \\
\text { task in the allotted time? }\end{array}$ & $4.4 \pm 0.38$ & $5.4 \pm 0.38$ \\
\hline & $\begin{array}{l}\text { How satisfied are you with your } \\
\text { design? }\end{array}$ & 0.23 & $4.8 \pm 0.34$ \\
\hline
\end{tabular}

Table 4. Comparison of Midpoint and Final Survey Results. Surveys measured on a 7-point Likert scale. Significant difference $(p=0.0632)$ between mid and final satisfaction for 5Design; no difference $(p=0.274)$ between mid and final satisfaction for 1-Design. Significant difference between 1Design time constraint in mid-survey and final survey $(p=0.0173)$.

\begin{tabular}{|c|c|c|c|}
\hline & Survey Question & $\begin{array}{l}\text { Midpoint } \\
\text { Survey } \\
(\text { Mean } \pm \mathrm{SE})\end{array}$ & $\begin{array}{l}\text { Final Survey } \\
(\text { Mean } \pm \text { SE) }\end{array}$ \\
\hline \multirow{3}{*}{ 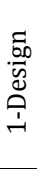 } & $\begin{array}{l}\text { How would you rate the technical } \\
\text { difficulty of the design task? }\end{array}$ & $3.7 \pm 0.25$ & $4.0 \pm 0.23$ \\
\hline & $\begin{array}{l}\text { How difficult was it to complete the } \\
\text { task in the allotted time? }\end{array}$ & $3.5 \pm 0.34$ & $4.4 \pm 0.38$ \\
\hline & How satisfied are you with your design? & $4.6 \pm 0.20$ & $4.7 \pm 0.27$ \\
\hline \multirow{3}{*}{ 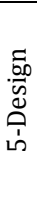 } & $\begin{array}{l}\text { How would you rate the technical } \\
\text { difficulty of the design task? }\end{array}$ & $3.7 \pm 0.3$ & $3.9 \pm 0.23$ \\
\hline & $\begin{array}{l}\text { How difficult was it to complete the task } \\
\text { in the allotted time? }\end{array}$ & $5.9 \pm 0.31$ & $5.5 \pm 0.38$ \\
\hline & $\begin{array}{l}\text { How satisfied are you with your } \\
\text { design? }\end{array}$ & $3.9 \pm 0.31$ & $4.8 \pm 0.34$ \\
\hline
\end{tabular}

\section{DISCUSSION}

This study was designed to determine if quickly creating more physical prototypes early in the design process would correlate with better performance of final prototypes. We also sought to answer other underlying questions: What are participants' perceived difficulties and general reflections about each design process? How can Kolb's theory of experiential learning inform the cognitive mechanisms of this pattern of prototyping? Can the corporate Second Toyota Paradox be applied to individual design efforts?

\subsection{DIVERGENT PROTOTYPING AS A DESIGN PARADIGM}

Survey data suggested that divergent prototyping is indeed fundamentally different from point-to-point iterative prototyping, both in terms of final design outcome and shaping the designer's perception of his or her prototypes. Participants who were instructed to create five prototypes (5-Design participants) expressed significantly greater time constraint and lower levels of satisfaction in their early prototypes. However, these participants exhibited significantly greater improvement in prototype performance between their first prototypes and their final prototype. Participants who were only instructed to design and construct one prototype (1-Design), on the other hand, showed no significant improvement in prototype performance between first and final prototypes. In short, creating more prototypes under the same shortened time constraints, though uncomfortable, did in fact improve design outcomes in subsequent iterations.

Interestingly, not only did the performance of 5-Design participants increase, but also their satisfaction. Survey responses indicated a significant increase in satisfaction in the prototype between completion of the first and final prototype. This observation aligns with our proposal that a new design process heavy in low-fidelity, low-quality physical models in early design stages would seem forced and unnatural in those 
early stages. Rather than converging ideas and settling on fewer designs before realizing them in three dimensions, the designer is compelled to produce many imperfect, explorative threedimensional models before even making a decision, thus exploring the design space more thoroughly than if they had only generated one concept.

Compare this to 1-Design participants, who, in terms of statistical significance, became neither more satisfied in their second prototypes nor achieved better performance. Increasing the quantity of prototypes a designer is forced to produce in early stages thus could affect the way in which the design artifact is perceived but the pay-off for engaging in greater exploration with preliminary models is greater improvement in performance in the final model. Participants, although initially apprehensive about initial ideas, in the end feel a greater sense of satisfaction, perhaps since the design space has been explored more fully and likely results in a better outcome.

\subsection{PROTOTYPING AS A COGNITIVE MECHANISM OF EXPERIENTIAL LEARNING IN DESIGN}

The implications of these results align well with Kolb's theory of experiential learning. Applied to this research challenge, experiential learning theory would assert that designers who spent early design stages diverging and interacting with these quickly-produced physical models would have an advantage over those who produced fewer preliminary prototypes and moved on. This is because, as the quantity of preliminary models created and explored increases, even as their individual quality suffers, the designer undergoes more repetitions of the learning cycle-forming and re-forming ideas as a result of vacillations between concrete and abstract, engaging all adaptive ability stages. Participants who divided time among multiple prototypes increased the quantity and breadth of interaction with their physical models, and thus were able to supplement their learning process with concrete feedback that their counterparts who remained mostly in abstract conceptualization were not able to do. Therefore, even though their preliminary prototypes may not have been as robust as 1-Design prototypes because each idea was given limited attention, 5-Design participants learned from those early interactions to improve upon their designs.

\subsection{COMPLEMENTARITY OF EXPERIENTIAL LEARNING AND CONCURRENT ENGINEERING}

In corporate contexts in which concurrent engineering has proven to be successful, the advantages of set-based design [15] are

1. Efficiency in communication, independence of subteams; decreased likelihood of one decision annulling a significant amount of work

2. Fluidity among design and manufacturing stages, allowing later stages to influence earlier ones

3. Evaluation of prototypes against a strong array of databased tests in the early stages of design

4. Collective learning acquired and deposited in institutional record
5. Achieving global maxima rather than "local optima" because design begins with a wide range of designs and pursues each in greater depth

Although some of these points are valid primarily in an interpersonal context, the philosophy and practical application of concurrent engineering with Kolb's experiential learning in design may be projected onto individual designers' experiences.

The optimization of experiential learning involves prolonging the process during which ideas are continuously developing through experience. Rather than viewing knowledge as a database of facts to be acquired and stored permanently, one can inform design decisions based on an ever-growing, ever-developing source of information that continuously updates based on real experience.

The premises of concurrent engineering thus lend themselves well to experiential learning. Devoting more time and energy to pursue multiple prototypes in greater depth increases the "cognitive surface area" on which experiential learning can occur. The opposite effect would be limiting this idea generation and exploration stage to the abstract field and moving forward with fewer designs without consulting other adaptive abilities that could contribute to learning.

In this way, although the pace of concurrent design may initially seem cumbersome and integrated abstract-concrete learning may also seem unnatural, the results of a fuller design experience which does not limit the design space from the beginning but instead slowly and purposefully contracts the design space is improved prototype performance.

\section{LIMITATIONS}

Although each of the experimental sessions were conducted successfully, our data does have some limitations in the number of participants and the number of prototypes actually produced in the 5-Design condition. While 5-Design participants were required to design five templates, not all of them were able to meet this goal because of the time constraint. A frequency chart of the data shows that a number of participants actually only produced one design (Figure 4).

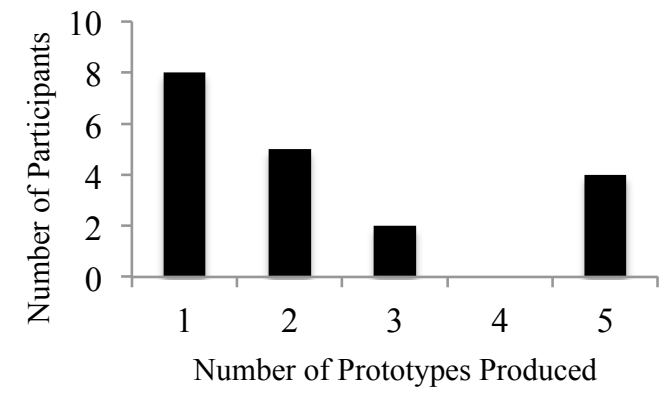

Figure 4. Frequency of number of prototypes produced in 5Design Case

However, we argue that this does not make a notable impact on our claims because 5-Design participants were cognizant of the time constraint and, regardless of how many 
templates actually submitted at the end of each iteration, operated with the goal of completing several prototypes. These participants were able to sketch more than one design or idea before they began building their templates, and their design decisions were made to accommodate the rapid turnover of preliminary ideas.

We also recognize the opportunity for improvement of the surveys given to participants at the mid and end points of the experiment. Further developed surveys, coupled with substantial concluding interviews, could give greater insight into the origin of and relationship between the varied levels of satisfaction and performance across experimental conditions.

\section{FUTURE WORK}

Osborn [23] delineated brainstorming as a collaborative mechanism engaged "for the sole purpose of producing a checklist of ideas...which can subsequently be evaluated and further processed." The power of this delayed judgment is evidenced in the ubiquitous use of brainstorming and its descendants as ideation tools. Similarly, Toyota has found benefit in the delayed decisions enabled via its documented setbased prototyping paradigm. The results of our present experiment, taken in light of these understood phenomena suggest the great potential of a technological means by which we might delay judgment in the interest of efficiently generating more and better ideas. Creation of an artifact - the intentional manipulation of order on a collection of raw materials to synthesize the physical representation of a mental construct - it would seem is, by definition, a convergent process. The mind, once engaged in the act of production, necessarily decides, constrains, judges and selects. However, through the use of rapid prototyping techniques, we believe that we've taken a small but important first step towards freeing the designer's cognition from the convergent forces of the fabrication process. Our preliminary findings may point the way to new design processes and tools, as well as ways to better use existing tools. Towards that end, we can anticipate refinements of the existing experiment that give us greater insight into (1) the designers' experience of the process, perhaps via a more substantial survey and interview protocol and (2) the mechanisms of idea evolution via a closer analysis of the ways in which concepts generated over time manifest in the final prototypes.

\section{ACKNOWLEDGMENTS}

The work described in this paper was supported in part by the National Science Foundation under Award CMMI-1130791. The opinions, findings, conclusions and recommendations expressed are those of the authors and do not necessarily reflect the views of the sponsors. We would also thank Dr. Tomonori Honda and Dr. Jonathan Adler for graciously lending their respective expertise our efforts.

\section{REFERENCES}

[1] Simon, H. A., 1969, The Sciences of the Artificial, MIT Press, Cambridge, MA.

[2] Bucciarelli, L. L., 1988, "An Ethnographic Perspective on Engineering Design," Design Studies, 9(3), pp. 159-168.

[3] Beckman, S. L., and Barry, M., 2007, "Innovation as a Learning Process: Embedding Design Thinking " California Management Review, 50(1), pp. 25-56.

[4] Owen, C., 1993, "Considering Design Fundamentally," Design Processes Newsletter, 5(3), p. 2.

[5] Houde, S., and Hill, C., 1997, "What do Prototypes Prototype?," Handbook of Human-Computer Interaction, M. Helander, T. Landauer, and P. Prabhu, eds., Elsevier Science, Amsterdam.

[6] Yang, M. C., 2005, "A study of prototypes, design activity, and design outcome," Design Studies, 26(6), pp. 649-669.

[7] Ullman, D. G., 2003, The Mechanical Design Process, McGraw-Hill, New York, NY.

[8] Sommerville, I., 1995, Software Engineering, AddisonWesley, Wokingham, England.

[9] Schrage, M., and Peters, T., 1999, Serious Play: How the World's Best Companies Simulate to Innovate, Harvard Business School Press, Boston, MA.

[10] Gerber, E., and Carroll, M., 2011, "The psychological experience of prototyping," Design Studies, 33(1), pp. 64-84.

[11] Hannah, R., Joshi, S., and Summers, J. D., 2012, "A user study of interpretability of engineering design representations," Journal of Engineering Design, 23(6), pp. 443-468.

[12] Verlinden, J., and Horv?th, I., 2009, "Analyzing opportunities for using interactive augmented prototyping in design practice," AI EDAM, 23(3), pp. 289-303.

[13] Campbell, R. I., De Beer, D. J., Barnard, L. J., Booysen, G. J., Truscott, M., Cain, R., Burton, M. J., Gyi, D. E., and Hague, R., 2007, "Design evolution through customer interaction with functional prototypes," Journal of Engineering Design, 18(6), pp. 617 - 635.

[14] Viswanathan, V. K., and Linsey, J. S., 2010, "Physical Models in Idea Generation: Hindrance or Help?," ASME International Design Engineering Technical Conferences, 2010(44137), pp. 329-339.

[15] Ward, A., Liker, J.K., Cristiano, J.J., and Sobek, D.K., 1995, "The Second Toyota Paradox: How Delaying Decisions Can Make Better Cars Faster," MIT Sloan Management Review, 36(3), pp. 43-61.

[16] Liker, J. K., and Morgan, J.M., 2006, "The Toyota Way in Services: The Case of Lean Product Development," Academy of Management Perspectives, 20(2), pp. 5-20.

[17] Sass, L., and Oxman, R., 2006, "Materializing design: the implications of rapid prototyping in digital design," Design Studies

Digital Design, 27(3), pp. 325-355.

[18] Kolb, D. A., 1984, Experiential Learning: Experience as the Source of Learning and Development, Prentice-Hall, Inc., Englewood Cliffs, N.J.

[19] Iliff, C. H., 1994, "Kolb Learning Style Inventory: A metaanalysis," Ph.D. Thesis, Boston University, Boston, MA. 
[20] Hickcox, L., 1991, "Kolb's experiential learning theory: An historical review and its effects in higher and adult education 1971-1991," PhD, Oregon State University, Corvallis, OR.

[21] Loch, C. H., Terwiesch, C., and Thomke, S.H., 2001, "Parallel and Sequential Testing of Design Alternatives," Management Science, 45(5), pp. 663-678.

[22] Shigley, J. E., and Mischke, C.R., 1989, Mechanical Engineering Design, McGraw-Hill, New York.

[23] Osborn, A. F., 1963, Applied Imagination, Charles Scribner and Sons, New York, NY. 